\title{
Knowledge and Attitudes of Hospital Nurses in Italy Related to Near-Death Experiences
}

\author{
Laura Cunico, R.N., Ed.D. \\ General Hospital, Verona, Italy
}

\begin{abstract}
I distributed Nina Thornburg's Near-Death Phenomena Knowledge and Attitudes Questionnaire to 750 nurses in three Verona hospitals, and received 476 completed questionnaires. Questionnaire respondents had a modest knowledge of near-death experiences (NDEs). Nevertheless, respondents expressed a positive attitude towards NDEs in general, and towards patients who had had NDEs. Thirty-four percent of the nurses had personally encountered NDErs, and those nurses reported a higher level of knowledge than their colleagues who had not had that opportunity. Furthermore, in relation to the global sample, nurses who had encountered an NDEr showed attitudes that were more positive regarding both the NDE itself and the type of assistance they offered NDErs.
\end{abstract}

KEY WORDS: knowledge; attitude; hospital nursing; NDE.

The scientific literature on the near-death experience (NDE) asserts that during a deep coma, a cardiac arrest, a head injury, or a clinical death, typical phenomena of altered consciousness may occur in at least a third of the patients concerned. This involves, for example, the potentiation of certain mental functions, such as the perception of colors, sounds, light and images; the sensation of separating from one's body and floating in the air; the ability to recall forgotten events from one's memory; the apparent movement of one's mind in time and space; experienced encounters with strangers not physically present; and a sense of positive, unaroused emotions, such as peace, serenity, and tranquility (Moody, 1975; Ring, 1980; Tiberi, 1994, 1996).

Laura Cunico, R.N., Ed.D., is a head nurse in the psychiatric ward of the General Hospital of Verona, and an assistant in the Institute of Psychology, University of Verona. Reprint requests should be addressed to Dr. Cunico at the Istituto di Psicologia, Università di Verona, via S. Francesco, 37129 Verona, Italy; e-mail: lacunico@tin.it. 
After a near-death experience, profound changes tend to take place in the personality, values, and attitudes. Experiencers perceive a profound sense of a personal rebirth, self-esteem, inner confidence, and appreciation of life in general; in addition, the fear of death diminishes and a belief in a future life after death increases (Greyson and Flynn, 1984; Sabom, 1982). NDErs develop a religious awareness tending towards an inner spirituality and, in an evolutionary sense, are perceived by some as precursors of a highly spiritual breed of men and women of the future, which has been called Homo noeticus (Ring, 1992).

Prior to the 1970s, the rare instances of reported NDEs were relegated to the field of parapsychology or mysticism, as the phenomenology of these experiences did not fit within a traditional scientific paradigm and, as such, were not considered an appropriate object of study. Medical progress in the area of cardiopulmonary resuscitation, and that of mobile emergency services with modern technical equipment, specialized personnel, helicopters, and ambulances, have made survival possible for many people who as a result of an illness, or an accident on the road or at the workplace, would otherwise die. Nowadays, doctors, nurses, and other hospital staff are increasingly in contact with NDErs and hear their personal accounts. Consequently, in order to understand the implications of the type of support and assistance that should be given to patients who have NDEs, it is important to investigate the knowledge of and attitudes toward NDEs of those people working in health services.

This article reports the findings of a study carried out in three public hospitals in Verona, Italy, in which the NDE knowledge and attitudes of nurses were surveyed in the critical areas (intensive care ward and emergency ward) and in the noncritical areas (department of internal medicine, surgical unit, geriatric ward, and others). One of the aims of this paper is to make the results of our survey readily available for practical purposes; that is, to encourage the development of permanent educational programs, and facilitate the nurse's task of assisting NDErs.

Our initial hypothesis assumed that the group of nurses working in the critical area, as opposed to the group of nurses in the noncritical area, would be more likely to encounter patients with NDEs and hear their accounts; consequently, they should have a greater awareness of the phenomenon and a more favorable attitude towards not only the problem in general, but also the NDErs themselves. 


\section{Brief Review of the Nursing Literature}

Scientific research on the knowledge and attitudes of nurses relating to NDEs is limited, even though the subject has received a great deal of attention over the last 25 years. In 1981, Annalee Oakes studied the attitudes of 30 nurses working in an intensive care ward. Her study showed that the majority of the nurses found the subject fascinating and about 50 percent of them felt it was useful for the patient to relate the experience to someone, though there were mixed opinions as to who the listener should be.

In 1986, Roberta Orne carried out a study on the attitudes and beliefs of 912 nurses related to NDEs. The results underscored a poor knowledge of the phenomenon. Though 58 percent of the participants had some familiarity with the NDE, they considered their knowledge of the subject to be "limited." Given the scarce amount of scientific literature on the subject related to nursing, the mass media turned out to be their only source of information. Yet despite this limited knowledge, the nurses displayed a positive attitude towards NDEs in that they listened to the patients' accounts and encouraged discussions about the experience ( 86 percent), and offered patients their support (69 percent). Only 2 percent of the participants had no idea whatsoever of how they should approach the patient, and 25 percent claimed they did not believe in these experiences. The nurses working in the emergency wards reported a higher level of knowledge than did the nurses in the maternity wards, while nurses in the psychiatric wards were more willing to listen to the NDE accounts. Interestingly, 28 percent of the nurses reported having had an NDE themselves.

In 1988, Nina Thornburg carried out a pilot study aimed at constructing a questionnaire that could measure the knowledge and attitudes concerning NDEs of 20 nurses working in an intensive care ward of a large Midwest American hospital. The study showed that 95 percent of the subjects had heard about the NDE, but none of them had personally had one. In 1991, Linda Barnett used Thornburg's questionnaire to survey a group of 60 nurses working in a number of hospices. The results showed that about 50 percent of the nurses were familiar with the NDE, and many of them had also worked with patients who had NDEs. All the participants in the study had a positive attitude towards near-death phenomena, and they were convinced that nurses should carefully listen to patients' entire accounts of their NDEs. In addition, the nurses agreed that patients with NDEs should receive the 
same type of nursing care as that received by patients who had not had an NDE.

\section{Method}

\section{Subjects}

The sample of nurses we interviewed was taken from the paramedic personnel lists supplied by the administrative offices of each hospital involved in our survey. The subjects were selected from three different hospitals in Verona: Ospedale Civile Maggiore di Borgo Trento, Policlinico di Borgo Roma, and Ospedale di Legnago (Verona).

After receiving permission from the authorities of each hospital, we began by distributing 750 questionnaires. The head nurses were given exact instructions for randomly selecting subjects to be given the questionnaires, and for collecting the completed questionnaires no later than two weeks after the subjects had received the questionnaires.

\section{The Research Tool}

The tool used in this study was Thornburg's (1988) Near-Death Phenomena Knowledge and Attitudes Questionnaire, translated into Italian by the Institute of Psychology, Verona University. The questionnaire is set out as follows: The first part asks about the respondent's professional qualifications, age, gender, and name of hospital in which the person works; in addition, the respondent is asked if he or she has ever encountered a patient with an NDE. The second part investigates the person's knowledge of NDEs, and is made up of 23 items with three possible answers: "true," "false," and "don't know." Knowledge scores are calculated using a value of 1 if the answer is correct, and a value of 0 if the answer is wrong or "don't know." Scores can range from 0 to 23 , and those who obtain a score of 12 or higher are considered to have a good level of knowledge of the phenomenon.

The third part is made up of 23 items that measure the nurse's general attitudes towards NDEs. In this section, the respondent is asked the degree to which he or she agrees or disagrees with each item, assigning a value for each item ranging from 1 (strong negative attitude) to 5 (strong positive attitude). Scores can range from 23 to 115 , and a score of 69 or higher indicates a positive attitude. The fourth part, consisting of 20 items in a 5-interval Likert scale format, measures the subject's attitudes to the types of treatments and assistance given to patients 
with NDEs. Scores on this section can range from 20 to 100 , and a score of 60 or higher suggests a positive attitude towards treating patients with NDEs.

\section{Statistical Analysis}

Mean values and percentages were calculated, and were evaluated statistically with $t$ tests, chi-squared tests, factor analyses, and linear correlation.

\section{Results}

\section{Sample}

From the 750 questionnaires that we distributed, a total of 476 (64 percent) were collected, of which 335 ( 71 percent) belonged to female participants and 136 ( 29 percent) to male participants. Our study group was relatively young (average age of 33.7 years), ranging from 20 to 60 years of age. The average age of the women was 31.3 years $(\mathrm{SD}=$ 8.0 ), and that of the men was 39.4 years $(\mathrm{SD}=9.3)$. As regards their professional qualifications, 44 respondents ( 9 percent) were head nurses, 370 (78 percent) were professional nurses, and 59 (13 percent) were general nurses. Thirty-four percent of the nurses claimed to have encountered patients who had told them about their NDE. The critical area sample consisted of 158 nurses (33 percent of the total), with a mean age of 31.4 years; and the noncritical area sample consisted of 317 nurses ( 67 percent), with a mean age of 34.7 years.

\section{Characteristics of the Questionnaire}

The scores for reliability of individual items of the questionnaire (item-total correlation) ranged from a minimum of $r^{2}=.13(p<.02)$ to a maximum of $r^{2}=.66(p<.001)$ for the nurses' general attitude scale, and a minimum of $r^{2}=.10(p<.02)$ and a maximum of $r^{2}=$ $.58(p<.001)$ for the attitude scale of nurses directly involved in treating NDErs. On the whole, our scores can be considered acceptable given the large number of subjects who completed questionnaires; however, the scores were lower than those found by Thornburg (1988), who used a much smaller sample in her study.

The validation trial with a factor analysis highlighted three factors regarding NDE knowledge. The first factor, which accounted for 
27 percent of the variance, referred to the characteristics of the NDE, its causes, its antecedents, and its aftereffects; the second factor, which accounted for 6 percent of the variance, grouped together a number of NDE elements such as ineffability and the presence of unaroused emotions such as peace, serenity, and tranquility; and the third factor, which accounted for 5 percent of the variance, highlighted the NDE as an objective and real phenomenon.

A factor analysis of the NDE general attitude scale highlighted four factors. The first factor, which accounted for 22 percent of the variance, referred to the nurses' future training; the second, which accounted for 12 percent of the variance, depicted the unfavorable attitudes of some nurses who felt that the nursing personnel should not be concerned with NDErs; the third factor, which accounted for 6 percent of the variance, described the NDE as a normal consciousness phenomenon; and the fourth, which accounted for 5 percent of the variance, concerned reporting, and grouped together a number of nursing tasks such as interviewing patients, informing doctors about patients' NDEs, and recording the event in the patient's file.

A factor analysis of the scale regarding the attitudes of those who care for patients with NDEs yielded three factors. The first factor, which accounted for 20 percent of the variance, was unfavorable towards the $\mathrm{NDE}$; the second, which accounted for 11 percent of the variance, depicted a positive attitude toward NDEs; and the third, which accounted for 6 percent of the variance, suggested that nurses should adopt a responsible attitude in dealing with the psychological problems of patients with NDEs.

On the basis of these results we may say that Thornburg's questionnaire can be considered reliable and valid in our Italian translation. All of Thornburg's items were used in our questionnaire, because their loadings were quite significant.

\section{The Investigation}

Knowledge of NDEs. The mean score for knowledge of NDEs in the global sample was $8.0(\mathrm{SD}=3.9$ ), which was rather low compared with the minimum value of 12 specified by Thornburg (1988) as reflecting "good" knowledge of NDEs. The Borgo Trento hospital nurses reported a mean score of 8.3 ( $\mathrm{SD}=3.5$ ); the Borgo Roma hospital nurses, 8.5 $(\mathrm{SD}=3.3)$; and the Legnago hospital nurses, $7.7(\mathrm{SD}=4.3)$.

The mean knowledge score for nurses in the critical areas of the three hospitals was 7.6 ( $\mathrm{SD}=3.7$ ), while the mean score for those in the 
noncritical areas was $8.3(\mathrm{SD}=4.0)$. Nurses in the noncritical areas in the Borgo Trento hospital had a higher score (mean $=8.9, \mathrm{SD}=3.5$ ) than did those in the critical area (mean $=7.7, \mathrm{SD}=3.4 ; t=2.01, \mathrm{df}=$ $164, p<.046$ ). Nurses in the critical area in the Borgo Roma hospital had a higher mean score $(8.9, \mathrm{SD}=2.8)$ than did those in the Legnago hospital (mean $=6.7, \mathrm{SD}=4.2 ; p<.041$ ).

As regards other variables, nurses' gender did not affect their knowledge either in the global sample or between hospitals. As regards the professional qualifications, the mean knowledge score for the head nurses $(9.0, \mathrm{SD}=4.2)$ and that for the professional and general nurses (mean $=8.0, \mathrm{SD}=3.9$ ) were not significantly different $(t=-1.498$, $\mathrm{df}=442 ; p=.135$ ).

As far as age was concerned, nurses older than 45 years in the Borgo Trento and Borgo Roma hospitals showed more knowledge about NDEs than did their younger colleagues. In the Borgo Trento hospital, the mean knowledge score of older nurses was $10.2(\mathrm{SD}=4.5)$, while that of the younger nurses was $8.0(\mathrm{SD}=3.1 ; t=2.19, \mathrm{df}=68 ; p<.032)$. At the Borgo Roma hospital, the mean knowledge score of the older nurses was $9.9(\mathrm{SD}=2.2$ ), while that of the younger nurses was 6.7 (SD $=2.0 ; t=-3.35, \mathrm{df}=19 ; p<.003$ ). The age variable would appear to favor those nurses who have had more opportunities during their professional careers to encounter NDErs or learn about the problem from other sources.

General Attitudes Toward the NDE. Among the global sample, the mean score for the general attitude towards the NDE was 80.6 (SD = $10.3)$ out of 115 . The nurses in the Borgo Trento hospital reported a score of $81.3(\mathrm{SD}=10.4)$; those in Borgo Roma, 82.7 (SD = 9.9); and those in Legnago, $79.1(\mathrm{SD}=10.3)$.

Among all three hospitals, nurses in the critical areas reported a mean score of $77.9(\mathrm{SD}=10.8)$, while those in the noncritical areas reported a significantly higher mean score of $82.0(\mathrm{SD}=9.8 ; t=-4.02$, $\mathrm{df}=434 ; p<.006)$. As in the case of knowledge, the general attitude scores were higher for the nurses working in the noncritical area of the Borgo Roma hospital $(84.0, \mathrm{SD}=9.2)$ than for the nurses in the same area in the Legnago hospital $(79.8, \mathrm{SD}=9.1 ; t=2.73, \mathrm{df}=87$; $p<.007$ ).

The mean general attitude scores for the male and female participants were not significantly different, except in the case of Borgo Trento, in which the female participants indicated a marginally more favorable attitude toward NDEs (mean $=82.2, \mathrm{SD}=9.7$ ) than did their 
male colleagues (mean $=78.9, \mathrm{SD}=11.8 ; t=1.93$, df $=183$; $p=.055$ ). In addition, the attitudes did not change with variations in age in any of the levels that were analyzed $(t=0.74, \mathrm{df}=154 ; p=$ $.461)$.

Finally, the head nurses, who are responsible for organizing the work tasks of the nurses in their wards, had a more favorable attitude towards the NDE (mean $=85.5, \mathrm{SD}=9.8$ ) than did the professional and general nurses (mean $=80.2, \mathrm{SD}=10.2 ; t=-3.23$, df $=433$; $p<.001$ ). The items that discriminated head nurses from other nurses concerned the importance of reassuring the patients that an NDE is a normal event and not a sign of mental disorder.

Attitudes in Caring for Patients Who Have Had an NDE. The mean score of the total sample for this aspect of the attitude study was 72.1 $(\mathrm{SD}=7.7)$, which was within the range of 60 to 100 suggested by Thornburg (1988) to represent favorable attitudes. The critical area sample reported a mean score of $71.0(\mathrm{SD}=7.8)$, while the noncritical area sample reported a mean score of $72.7(\mathrm{SD}=7.5$ ). Nurses in the Borgo Trento hospital obtained a mean score of $74.2(\mathrm{SD}=8.0)$ in the noncritical area, significantly higher than in the critical area (mean $=70.8$, $\mathrm{SD}=6.9 ; t=-3.14, \mathrm{df}=184, p<.002$ ). The differences were brought about by those items that emphasized the importance of keeping an open mind to what was heard, showing a willingness to offer the same type of care in qualitative terms to patients with and without NDEs, and recognizing the nurse's duty to listen carefully to their patients' NDE accounts and to take them seriously.

The Borgo Trento hospital reported a score of $72.6(\mathrm{SD}=7.7)$; the Borgo Roma hospital, 73.6 (SD = 8.2); and the Legnago hospital, 71.0 $(\mathrm{SD}=7.3)$. The chi-squared analysis revealed a significant difference among the three hospitals ( $\chi^{2}=3.57, \mathrm{df}=2 ; p=.029$ ), with nurses in the Borgo Roma hospital, the university teaching and research center, having the most favorable attitude.

With regard to gender, there were no significant differences for the global sample, but there was a difference in the Borgo Roma hospital, where the women's mean score was $74.9(\mathrm{SD}=6.4)$ and the men's was $70.5(\mathrm{SD}=10.6 ; t=2.19, \mathrm{df}=72 ; p=.032)$. There were no significant differences in this type of attitude for the age groups that were analyzed $(t=-0.11, \mathrm{df}=156 ; p=.912)$. Once again, the head nurses reported a higher mean score of $75.6(\mathrm{SD}=7.4)$ than did the professional and general nurses (mean $=71.7, \mathrm{SD}=7.6 ; t=-3.18, \mathrm{df}=443 ; p<.002$ ). 
Nurses Who Had Encountered NDErs. Thirty-four percent of the nurses claimed they had encountered NDErs. Their mean knowledge score was $8.9(\mathrm{SD}=3.2)$, which was higher than that for nurses who had not had an encounter with an NDEr (mean $=7.6, \mathrm{SD}=4.1 ; t=$ $3.13, \mathrm{df}=184 ; p<.002$ ). In the critical areas of the three hospitals the knowledge score for those nurses who had encountered an NDEr (mean $=8.4, \mathrm{SD}=2.9$ ) was higher than that of the nurses who had never encountered an $\mathrm{NDEr}$ (mean $=7.0, \mathrm{SD}=4.0 ; t=2.15$, $\mathrm{df}=127$; $p=.033)$. The same can be said for the noncritical area $(t=-2.60, \mathrm{df}=$ $289 ; p<.01)$.

If we look at the hospitals on an individual basis, we can see for example that in the critical area of Borgo Trento those who had encountered NDErs (mean $=8.7, \mathrm{SD}=2.3$ ) reported scores that were significantly higher than those who had not had any such encounter (mean $=6.8, \mathrm{SD}=3.9 ; t=2.545, \mathrm{df}=68 ; p=.013$ ). Nevertheless, the score for nurses in the noncritical area (mean $=10.3, \mathrm{SD}=3.2$ ) was even higher $(t=-2.787, \mathrm{df}=88 ; p=.007)$. In the noncritical area of the Legnago hospital, the nurses who had encountered NDErs had a score (mean $=9.0, \mathrm{SD}=3.5$ ) that was marginally higher than that of the nurses who had not encountered NDErs (mean $=7.5, \mathrm{SD}=4.6 ; t=$ $-1.91, \mathrm{df}=153 ; p=.058$ ).

The results obtained from the critical area of the Borgo Roma hospital confirmed that scores tend to be higher for nurses who had encountered NDErs (mean $=9.1, \mathrm{SD}=3.0$ ) than for their colleagues who had not (mean $=8.7, \mathrm{SD}=2.8$ ), although that difference was not significant $(t=-0.27, \mathrm{df}=19 ; p=.789)$.

The attitude score of the nurses who had encountered NDErs was 81.1 ( $\mathrm{SD}=9.6$ ), with a score of $73.0(\mathrm{SD}=7.5)$ for their attitude in caring for NDErs. Nurses in the noncritical area of Borgo Trento who had encountered NDErs obtained a score for their attitude towards caring for NDErs (mean $=77.5, \mathrm{SD}=6.7$ ) that was significantly higher $(t=-2.80, \mathrm{df}=95 ; p=.006)$. Similarly, in the critical area of the Legnago hospital, the nurses who had encountered NDErs obtained a mean score of $81.6(\mathrm{SD}=8.6)$ in their attitude toward caring for NDE patients, which was a significantly higher score than that obtained by nurses who had not encountered NDErs (mean = $72.9, \mathrm{SD}=11.5 ; t=2.20, \mathrm{df}=30 ; p=.036$ ). In contrast, an opposite tendency was observed for nurses who had encountered NDErs in the noncritical area of the same hospital: they obtained lower scores in their general attitude (mean $=76.9, \mathrm{SD}=8.5$ ) than did those who had 
not encountered NDErs (mean $=80.9, \mathrm{SD}=9.3 ; t=2.33, \mathrm{df}=127$; $p=.021)$.

\section{Discussion}

Our initial hypothesis assumed that nurses in the critical areas would have greater knowledge of and better attitude towards NDEs and its related problems, because there was a higher probability of encountering patients with NDEs in the critical area than in the noncritical areas. That hypothesis was not confirmed by the data in our research. In contrast to the original hypothesis, the noncritical areas offers a greater opportunity of encountering NDErs than did the critical areas; 63 percent of the nurses in our survey who had encountered NDErs had done so in the noncritical areas, and only 37 percent in the critical areas. Nevertheless, the fact that the nurses who had encountered NDErs also had a better knowledge of and attitude towards the NDE and its related problems confirms the logic that underlay the initial hypothesis of this paper; that is, knowledge of the phenomenon leads to a better attitude toward patients who have NDEs.

\section{Comparison with Similar Studies}

There have been at least four previously published studies carried out using Thornburg's questionnaire. Barbara Walker and Robert Russell (1989) surveyed psychologists, who reported a mean score of 7.5 for their knowledge and a score of 61.3 out of 85 for their attitude to NDE. Nineteen percent of the psychologists surveyed reported having treated patients who had had an NDE, while 28 percent had had some form of personal contact with NDErs. Linda Barnett (1991) surveyed 60 nurses working in American hospices, who reported a mean knowledge score of $\mathbf{1 0 . 6}$ and a general attitude score of 89.0 , while the score for their attitude towards patients with NDEs was 79.3.

Lori Bechtel, Alex Chen, Richard Pierce, and Walker (1992) surveyed 320 clergymen, who reported a score of 7.8 for their knowledge and 49 out of $\mathbf{8 5}$ for their attitude. In a follow-up to her study of hospice nurses, Barnett, writing under her maiden name Linda Moore (1994), surveyed 170 physicians, who reported a knowledge score of 7.4 and an attitude score of 91.0. The doctors in that study felt they could obtain a better understanding of NDEs by attending special courses on the subject, and they were convinced that the nursing staff would also benefit from such courses. 
Our survey cannot be compared with studies using a different analytical tool from Thornburg's questionnaire, some of which have been cited above, or those done by Walker and Russell (1989), Bechtel, Chen, Pierce, and Walker (1992), or Moore (1994), who significantly modified Thornburg's questionnaire in their studies. We used the same version in our survey as the one used by Barnett (1991). The Barnett (1991) study, as described above, reported higher scores for both knowledge and attitudes than did our survey done in Verona. The reason for this difference may be that near-death research in the United States began about 10 years before it did in Italy; consequently, since the subject had been popularized in the United States first, one might legitimately hypothesize that American nurses are better informed than Italian ones.

\section{Interpretation of Our Data}

The purposes of our study were both to verify the validity of Thornburg's questionnaire in Italian translation and to analyze the NDE knowledge and attitudes of nurses working in hospitals in Verona. Our results prove that the tool is reliable and valid in Italian translation. Consequently, these results enable us to consider the data obtained from the Verona survey, which was carried out with the abovementioned questionnaire, as valid.

Our finding that nurses in the Borgo Roma hospital critical areas had a higher mean knowledge score than did those in the Legnago hospital may be explained by the fact that the Borgo Roma hospital is a general hospital of the university and functions as a research and training center; therefore, the level of knowledge of its personnel is higher. Our finding that the Borgo Roma critical area nurses had higher scores for general attitude toward NDEs than did their counterparts in the Legnago hospital is probably due to the same factor.

In addition, our results show some differences in level of knowledge between nurses of critical and noncritical areas. The noncritical area nurses turned out to be those with a higher knowledge in each of the three hospitals; this may be due to the fact that the nurses in these areas are older, and age is directly correlated with knowledge. Furthermore, the probability of encountering NDErs is higher in the noncritical areas. In many instances, this is due to the fact that by the time patients are in a condition to recount their experiences, they have already been transferred out of the critical area and into a noncritical area. This explanation has been confirmed in the case of Verona hospitals in a previous study done by Elena Montresor (1992), who was unable to 
recruit NDErs in the critical areas of the Borgo Roma and Borgo Trento hospitals, but instead found them in noncritical areas such as the longterm patient facilities of the Negrar hospital in Verona.

Our finding that older nurses in the Borgo Trento and Borgo Roma hospitals were better informed about NDEs than were their younger colleagues suggests that older nurses, which we defined as older than 45 years, may have had more opportunities during their longer professional careers to encounter patients with NDEs or to learn about NDEs from other sources. Our finding that head nurses had more favorable attitudes toward NDEs than did professional and general nurses may be due to the fact that the head nurses have had a higher level of training and more professional experience.

Furthermore, our results show that nurses in Verona have little knowledge regarding the NDE phenomenon, and that the reason for this lack of awareness is to be found in the fact that the NDE is not included in any of the study or training programs for nurses. In addition, scientific research on NDEs in Italy is lacking, and the subject is, in part, ignored by the scientific community. In fact, there are very few Italian researchers who study this phenomenon. Associations concerned with this problem do not exist, and there does not exist any scientific journal treating this subject. Only the mass media has given some attention to NDE phenomena, and only in recent years.

Despite this lack of knowledge, the general attitude of our nurses toward NDEs was largely positive. Nurses in the noncritical areas were significantly more favorable than were those in the critical areas. The Borgo Roma hospital, which is a general hospital and university research center, turned out to be the one in which the nurses were most favorable and most informed. The head nurses are also more favorable towards the NDE.

Everything that has been said so far leads us to conclude that information influences attitudes more than any other variable. Other authors have previously reported that information and attitude are correlated to each other (Bechtel, Chen, Pierce, and Walker, 1992; Hayes and Orne, 1990; Walker and Russell, 1989). As regards the attitudes towards caring for NDErs, the results showed they were positive for both the global sample and the individual hospitals. Once again Borgo Roma and the head nurses had the most favorable attitudes.

Encounters with NDErs played an important role in favoring knowledge about NDEs in both the global sample and the noncritical areas. Obviously, those nurses who had encountered patients with NDEs also 
had a greater opportunity of knowing about the NDE; and in addition, the probability of an encounter would appear to be higher in noncritical areas, hospitals with long-term patients, and rehabilitation centers, as noted above. Naturally, an encounter with an NDEr also plays an important part in the general attitude profile of nurses, as it favors the forming of a positive attitude towards NDEs and toward caring for patients with NDEs, which would logically follow from the inherent relationship between knowledge and attitudes.

\section{Nursing Implications and Conclusions}

Knowledge of near-death phenomenology on the part of the nurses operating in the pain treatment wards could become an aid or a tool to be used in caring for dying patients. In the majority of these cases, the nurse's form of communication is aimed at creating an atmosphere that releases the patient's tension, fear, and anguish, thereby improving the quality of the patient's condition.

Present-day scholars concerned with nursing models and theories of systems (Johnson, 1980; Rogers, 1970), nursing development (Hall, 1965; Orem, 1990), and nursing interaction (Peplau, 1952; Watson, 1989) agree on a holistic approach to nursing and a metaparadigm of nursing that includes the four concepts of person, environment, health, and care. Among various interaction models and theories, Hildegard Peplau's model (1952) of interpersonal relations may be the most appropriate in dealing with the problems of NDEs and nursing practices. Peplau focused on the humanistic component of nursing, on the psychological plane involving components of the nurse's personality and behavior. According to Peplau, nursing consists of helping by means of the nurse/patient relationship. Psychodynamic nursing applies the principles of human relations to problems that arise on all levels of human experience. Peplau indicated four stages in the nurse/patient relationship: orientation, identification, utilization, and resolution. During this process, the nurse assumes different roles, such as advisor, teacher, guide, expert, or substitute. In the light of the interpersonal relations model, an adequate knowledge of near-death phenomena and a positive attitude toward them enable the nurse to understand the patient reporting an NDE and thus to help the patient identify the problematic elements involved in his or her situation. The nurse must be prepared not only to listen to, inform, and reassure the patient, but also to provide valid moral and psychological support. 


\section{References}

Barnett, L. (1991). Hospice nurses' knowledge and attitudes toward the near-death experience. Journal of Near-Death Studies, 9, 225-232.

Bechtel, L. J., Chen, A., Pierce, R. A., and Walker, B. A.(1992). Assessment of clergy knowledge and attitudes toward near-death experiences. Journal of Near-Death Studies, 10, 161-170.

Greyson, B., and Flynn, C. P.(1984). The near-death experience: Problems, prospects, perspectives. Springfield, IL: Charles C Thomas.

Hayes, E. R., and Orne R. M. (1990). A study of the relationship between knowledge and attitudes of nurses in practice related to the near-death experience. Loss, Grief, and Care, 4, 71-80.

Hall, L. (1965). Nursing: What is it? In Baumgarten, H. (Ed.), Concepts of nursing home administration. New York, NY: Macmillan.

Johnson, D. E. (1980). The behavioral system model for nursing. In Riehl, J. P., and Roy, C. (Eds.), Conceptual models for nursing practice, $2^{\text {nd }}$ ed. (pp. 207-216). New York, NY: Appleton-Century-Crofts.

Montresor, E. (1992). Coscienza e coma: Ricerca empirica su attività mentali coscienti durante il coma profondo [Consciousness and coma: An empirical study of conscious mental activity during deep coma]. Unpublished doctoral dissertation, Università di Verona, Verona, Italy.

Moody, R. A. (1975). Life after life. Covington, GA: Mockingbird Books.

Moore, L. H. (1994). An assessment of physicians' knowledge of and attitudes toward the near-death experience. Journal of Near-Death Studies, 13, 91-102.

Oakes, A. (1981). Near-death events and critical care nursing. Topics in Clinical Nursing, 3(3), 61-78.

Orem, D. E. (1990). Nursing: Concepts of practice, $4^{\text {th }}$ ed. St. Louis, MO: Mosby-Year Book.

Orne, R. M. (1986). Nurses' views of NDEs. American Journal of Nursing, 86, 419-420.

Peplau, H. E. (1952). Interpersonal relations in nursing: A conceptual frame of reference for psychodynamic nursing. New York, NY: Springer.

Ring, K. (1980). Life at death: A scientific investigation of the near death experience. New York, NY: Coward, McCann and Geoghegan.

Ring, K. (1992). The Omega Project: Near-death experiences, UFO encounters, and mind at large. New York, NY: Morrow.

Rogers, M. E.(1970). An introduction to the theoretical basis of nursing. Philadelphia, PA: F. A. Davis.

Sabom, M. B. (1982). Recollections of death: A medical investigation. New York, NY: Harper and Row.

Thornburg, N. (1988). Development of the Near-Death Phenomena Knowledge and Attitudes Questionnaire. Journal of Near-Death Studies, 6, 223-238.

Tiberi, E. (1994). "Aporie" della coscienza: Ricerca empirica sulla presenza-assenza di attività mentali coscienti durante malattie con reale rischio di morte [The apparent inconsistencies of consciousness: A study of simultaneous absence-presence of mental activity in near-death illness]. Archivio di Psicologia Neurologia e Psichiatria, 54, 139166.

Tiberi, E. (1996). Hedonic deactivation: A new human value for an advanced society. Journal of Near-Death Studies. 15, 55-69.

Walker, B. A., and Russell, R. D. (1989). Assessing psychologists' knowledge and attitudes toward near-death phenomena. Journal of Near-Death Studies, 8, 103-110.

Watson, J. (1988). Nursing: Human science and human care-a theory of nursing. New York, NY: National League for Nursing. 